ARTICLE

\title{
LRP6 acts as a scaffold protein in cardiac gap junction assembly
}

Jun $\mathrm{Li}^{1,2, \star}$, Changming $\mathrm{Li}^{1,3, \star}$, Dandan Liang ${ }^{1,2, \star}$, Fei Lv ${ }^{1,3, \star}$, Tianyou Yuan ${ }^{1,3}$, Erlinda The ${ }^{1,3}$, Xiue Ma Ma, Yahan Wu ${ }^{1,3}$, Lixiao Zhen ${ }^{1,3}$, Duanyang Xie ${ }^{1,3}$, Shiyi Wang ${ }^{1,3}$, Yuan Liu' ${ }^{1,3}$, Jian Huang ${ }^{1,3}$, Jingyi Shi ${ }^{4}$, Yi Liu ${ }^{1,2}$, Dan Shi ${ }^{1,2}$, Liang $\mathrm{Xu}^{1,2}$, Li Lin ${ }^{1,2}$, Luying Peng ${ }^{5}$, Jianmin Cui ${ }^{4}$, Weidong Zhu ${ }^{1,3} \&$ Yi-Han Chen ${ }^{1,2,3,5}$

Low-density lipoprotein receptor-related protein 6 (LRP6) is a Wnt co-receptor in the canonical Wnt/ $\beta$-catenin signalling. Here, we report the scaffold function of LRP6 in gap junction formation of cardiomyocytes. Cardiac LRP6 is spatially restricted to intercalated discs and binds to gap junction protein connexin 43 (Cx43). A deficiency in LRP6 disrupts Cx43 gap junction formation and thereby impairs the cell-to-cell coupling, which is independent of Wnt/ $\beta$-catenin signalling. The defect in $\mathrm{C} \times 43$ gap junction resulting from LRP6 reduction is attributable to the defective traffic of de novo $\mathrm{C}_{x} 43$ proteins from the endoplasmic reticulum to the Golgi apparatus, leading to the lysosomal degradation of $\mathrm{C} \times 43$ proteins. Accordingly, the hearts of conditional cardiac-specific Lrp6-knockout mice consistently exhibit overt reduction of $\mathrm{C} \times 43$ gap junction plaques without any abnormality in Wnt signalling and are predisposed to lethal arrhythmias. These findings uncover a distinct role of LRP6 as a platform for intracellular protein trafficking.

\footnotetext{
${ }^{1}$ Key Laboratory of Arrhythmias of the Ministry of Education of China, East Hospital, Tongji University School of Medicine, Shanghai 200120, China. ${ }^{2}$ Institute of Medical Genetics, Tongji University, Shanghai 200092, China. ${ }^{3}$ Department of Cardiology, East Hospital, Tongji University School of Medicine, Shanghai 200120, China. ${ }^{4}$ Cardiac Bioelectricity and Arrhythmia Center, and Department of Biomedical Engineering, Washington University, St Louis, Missouri 63130, USA. ${ }^{5}$ Department of Pathology and Pathophysiology, Tongji University School of Medicine, Shanghai 200092, China. ${ }^{\star}$ These authors contributed equally to this work. Correspondence and requests for materials should be addressed to Y.-H.C. (email: yihanchen@tongji.edu.cn).
} 
W nts are secreted glycoproteins that activate evolutionarily conserved intracellular signalling cascades ${ }^{1}$. The Wnt signal has distinct transcriptional outputs, which determine cell proliferation, polarity and fate during embryonic development and tissue homeostasis ${ }^{2,3}$. The term Wnt is a combination of the Drosophila gene, wingless, and the vertebrate homologue, Int-1 (ref. 1). As currently understood, Wnt proteins bind to frizzled receptors on the cell surface, and the resulting signal is transduced through several cytoplasmic relay components to $\beta$-catenin, which enters the nucleus and forms a complex with T-cell factor (TCF) to activate transcription of Wnt target genes ${ }^{3}$. For the interaction between Wnts and frizzled, co-receptors are commonly required ${ }^{4}$. The low-density lipoprotein receptor-related protein 6 (LRP6) is a documented co-receptor that mediates Wnt signalling dependent on $\beta$ catenin $^{4,5}$.

Cumulative studies have demonstrated that participants in the Wnt signalling pathway play important roles in cardiovascular development and differentiation, angiogenesis, cardiac hypertrophy, cardiac failure and aging ${ }^{6-1}$. Given the central regulatory role of LRP6 in mediating the activation of the Wnt/ $\beta$-catenin pathway ${ }^{4,5}$, germ-line knockout of Lrp6 impairs Wnt signal transduction, thereby causing embryonic lethality in mice ${ }^{12}$. Mutations in the gene encoding LRP6 protein are implicated in human coronary artery disease ${ }^{13,14}$. However, additional new insights into the biological and physiological activities of LRP6 protein in the normal adult heart await further characterization.

In the present study, we uncovered a novel molecular property of LRP6, beyond its role as a Wnt co-receptor, in regulating connexin $43(\mathrm{Cx} 43)$ gap junction-mediated intercellular communication. Reduction of LRP6 induced the retention of newly synthesized Cx43 in the endoplasmic reticulum (ER) and thereby promoted the lysosomal degradation of immature Cx43 proteins, which resulted in the impaired formation and function of gap junctions. Moreover, although LRP5 and LRP6 are highly homologous, the evidence obtained in this study excludes the potential contribution of LRP5 to Cx43 expression and the regulation of LRP6 on Cx43 gap junction. In summary, this study identified the novel scaffolding role of LRP6 in controlling intracellular $\mathrm{Cx} 43$ traffic and gap junction formation in the heart.

\section{Results}

LRP6 associates with Cx43 gap junction in cardiac myocytes. To analyse the cell biology of LRP6 in the heart, we first utilized confocal microscopy combined with immunofluorescence staining to visualize the cellular localization of LRP6. In freshly isolated, intact adult rat ventricular cardiomyocytes (Fig. 1a) and heart sections (Fig. 1b), LRP6 was predominantly stained at intercalated discs. Considering that gap junctions, principally composed of $\mathrm{Cx} 43$ proteins, are specialized intercellular connections between myocytes in the ventricle ${ }^{15,16}$, we next performed co-localization analysis of LRP6 and Cx43 in cardiomyocytes. The results showed nearly complete overlap of LRP6 with Cx43 (Fig. 1c,d). In accordance, LRP6 co-precipitated with $\mathrm{Cx} 43$ (Fig. 1e), which verified the physical interactions between endogenous LRP6 and Cx43. Interestingly, although LRP5 and LRP6 are transmembrane proteins whose large extracellular domains are highly related $^{5}$, LRP5 did not interact with $\mathrm{Cx} 43$ (Supplementary Fig. 1a-e). Moreover, $\beta$-catenin, the key downstream effector of Wnt signalling ${ }^{3}$, was partially co-localized with $\mathrm{Cx} 43$ (Supplementary Fig. 1f). Collectively, the distinct cellular localization of LRP6 and the physical interaction of LRP6 and Cx43 suggest the potential regulation of $\mathrm{Cx} 43$ gap junctions in the heart by LRP6.
Knockdown of LRP6 disrupts $\mathrm{Cx} 43$ gap junctions. To explore the potential effect of LRP6 on Cx43 gap junctions, Lrp6 knockdown was conducted in cultured primary neonatal rat ventricular myocytes (NRVMs) using adenovirus-delivered small interfering RNAs (siRNAs) against the Lrp6 transcript (Ad-Lrp6 short hairpin RNA (shRNA)). The knockdown efficacies of three independent Lrp6 siRNAs were preliminarily verified in NRVMs (Fig. 2a), and the most effective siRNA sequence was adopted to generate a high titre of Ad-Lrp6 shRNA adenovirus. A reduction in LRP6 significantly depressed the protein expression of $\mathrm{Cx} 43$ (Fig. 2a), which was validated by overexpression of shRNA-resistant human Lrp6 (Fig. 2b). LRP6 deficiency did not affect other proteins responsible for cell-cell junctions, including $\mathrm{Cx} 40, \mathrm{Cx} 45$ and $\mathrm{N}$-cadherin (a transmembrane protein mediating cell-cell adhesion) (Supplementary Fig. 2a-d). Confocal fluorescence immunohistochemistry of NRVMs also confirmed the reduction in $\mathrm{Cx} 43$ protein levels and allowed for the visualization of the disruption of gap junction plaque formation in the presence of Ad-Lrp6 shRNA (Fig. 2c). We next considered whether the reduction of $\mathrm{Cx} 43$ and the disruption of gap junction plaque by Lrp6 knockdown have a functional effect on cell-to-cell coupling. Because gap junction channels composed of $\mathrm{Cx} 43$ are highly permeable to the fluorescent dye Lucifer Yellow, we tested the extent of intercellular transfer of the gap junction permeant Lucifer Yellow. As shown in Fig. 2d, the number of visibly fluorescent neighbour cells after injection into a centrally situated myocyte was significantly reduced in LRP6-deficient NRVMs, suggesting a defect in cell-to-cell coupling via Cx43 gap junctions. In contrast to the profound effects of Lrp6 knockdown on Cx43 proteins, $\mathrm{Cx} 43$ reduction did not affect protein levels of LRP6 (Fig. 2e). It is worth noting that knockdown of Lrp5 in NRVMs did not change Cx43 protein expression and gap junction formation, neither did LRP5 overexpression counteract the downregulation of $\mathrm{Cx} 43$ caused by LRP6 deficiency (Supplementary Fig. 3). These results indicate that LRP6 regulates the protein expression of $\mathrm{Cx} 43$, thereby affecting $\mathrm{Cx} 43$-dependent gap junction formation and function in cardiomyocytes.

LRP6 comprises four tandem $\beta$-propeller-epidermal growth factor-like domains (PE), LDLR type A domain (LA) and cytoplasmic domain (CD). To further identify the potentially key domains of LRP6 in regulating the protein expression of Cx43, we engaged multiple truncated mutants of LRP6 (Supplementary Fig. 4a). Overexpression of the truncated mutant with deletion of the first-to-second $\beta$-propeller-epidermal growth factor domain $(\triangle \mathrm{P} 1 \mathrm{E} 1 \mathrm{P} 2 \mathrm{E} 2)$ rather than of the other modules $(\triangle \mathrm{P} 3 \mathrm{E} 3 \mathrm{P} 4 \mathrm{E} 4$ and $\triangle \mathrm{LA}-\mathrm{CD})$ of LRP6 significantly downregulated the protein levels of $\mathrm{Cx} 43$ (Supplementary Fig. 4b), which was similar to the effect of silencing the full-length LRP6. In addition, we found that the LRP6-P1E1-P2E2 module was also responsible for the binding of LRP6 to Cx43 (Supplementary Fig. 4c), suggesting that the LRP6 P1E1-P2E2 domain is essential for the LRP6-dependent regulation of $\mathrm{Cx} 43$ protein expression.

LRP6 regulates Cx43 expression independent of Wnt signalling. Previous studies have suggested that $\mathrm{Cx} 43$ is a functional target for $\mathrm{Wnt} / \beta$-catenin signalling ${ }^{17-19}$. Both Wnt ligands and lithium (an ion that mimics Wnt signalling) activate $\beta$-catenin to induce transcriptional activation of the $C x 43$ promoter and increase $C \times 43$ protein expression ${ }^{18,19}$. In the absence of a Wnt ligand, LRP6 is inactive; consequently, $\beta$-catenin is degraded via the proteasome ${ }^{5}$. We assessed whether LRP6 deficiency depressed the expression of $\beta$-catenin, and, if so, the potential association of this process with reduced Cx43 expression. Surprisingly, although the reduction in $\beta$-catenin reduced Cx43 protein levels (Fig. 3a), LRP6 deficiency 
a

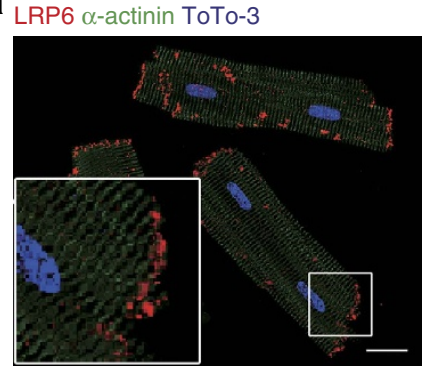

C
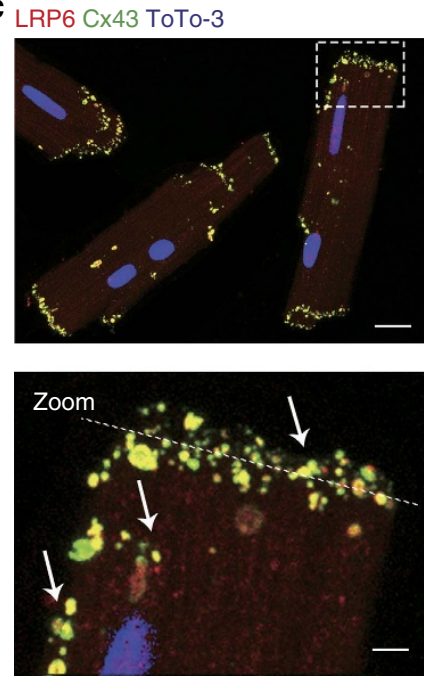

Overlap $R=0.95$

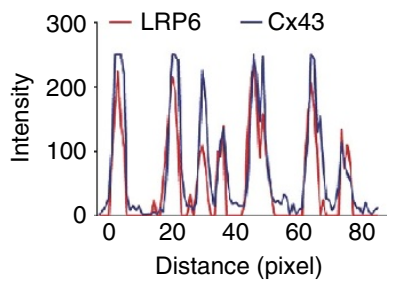

e

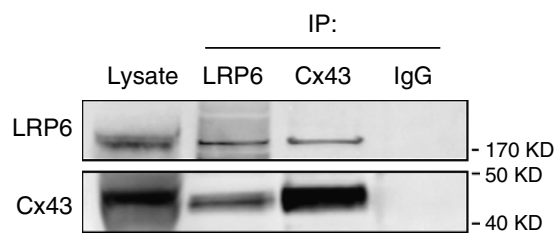

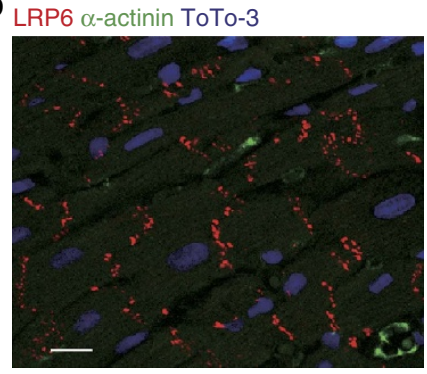

$\mathbf{d}_{\text {LRP6 } 6 \times 43 \text { ToTo-3 }}$
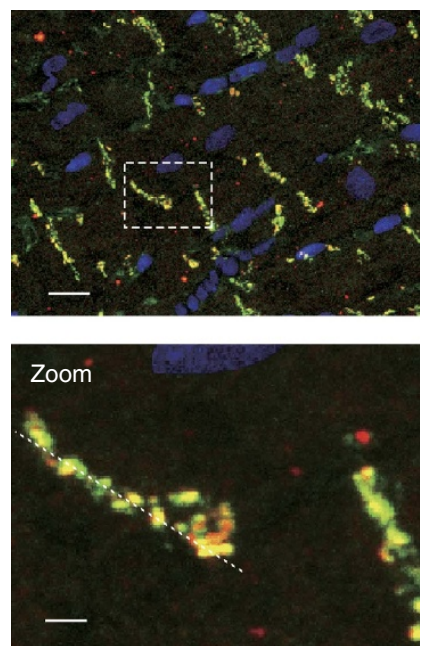

Overlap $R=0.94$
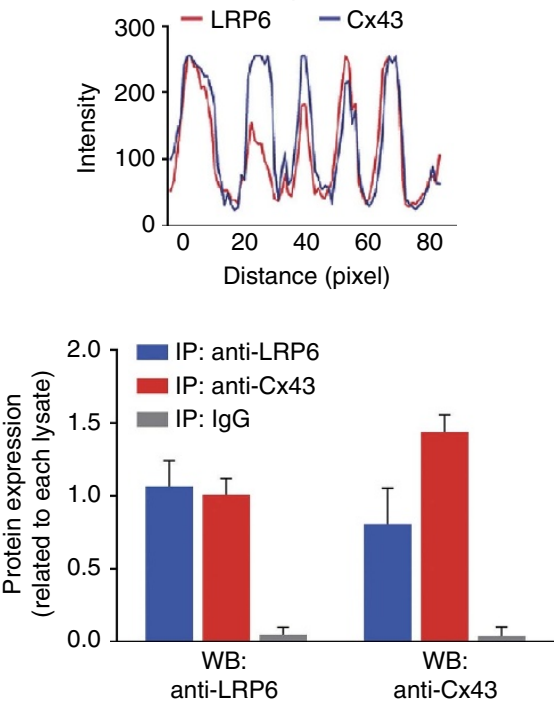

Figure 1 | Spatial distribution of LRP6 in cardiomyocytes and ventricular tissues. (a,b) Immunofluorescence staining of endogenous LRP6 in intact adult mouse ventricular myocytes (AMVMs) (a) and intact adult mouse ventricular tissues (b). Scale bars, $25 \mu \mathrm{m}$. Magnified images indicates the distribution patterns of LRP6 in the white boxes. (c,d) Immunofluorescence labelling of endogenous LRP6 and Cx43 in intact AMVMs (c) and intact adult mouse ventricular tissues (d). Magnified images indicating co-localization of LRP6 with Cx43 are shown in the white boxes. Upper, scale bars, $25 \mu \mathrm{m}$; Middle, scale bars, $5 \mu \mathrm{m}$. The bottom row indicates Pearson's correlation coefficient $(R)$ and line plot profiles. (e) Co-immunoprecipitation of endogenous LRP6 and Cx43 in intact AMVMs. Left, typical blots; right, pooled data. $n=3$. Data are means \pm s.e.m. $n$ represents the number of experiments. The presented images and blots are representative of three separate experiments.

did not alter the protein expression and cellular distribution of $\beta$-catenin in NRVMs (Supplementary Fig. 5a-c). In normal cardiomyocytes, Wnt activation and inhibition with Wnt3a and LGK-974 did not affect the membrane distribution and interaction of LRP6 and Cx43 (Supplementary Fig. 5d). On exposure to lithium chloride and Wnt3a-conditioned medium (Fig. 3a-c), the protein levels of $\beta$-catenin were upregulated in LRP6-deficient NRVMs; however, the reductions in $\mathrm{Cx} 43$ protein expression and gap junction formation were not ameliorated (Fig. 3d). These results indicate that LRP6 is not indispensable for 
a
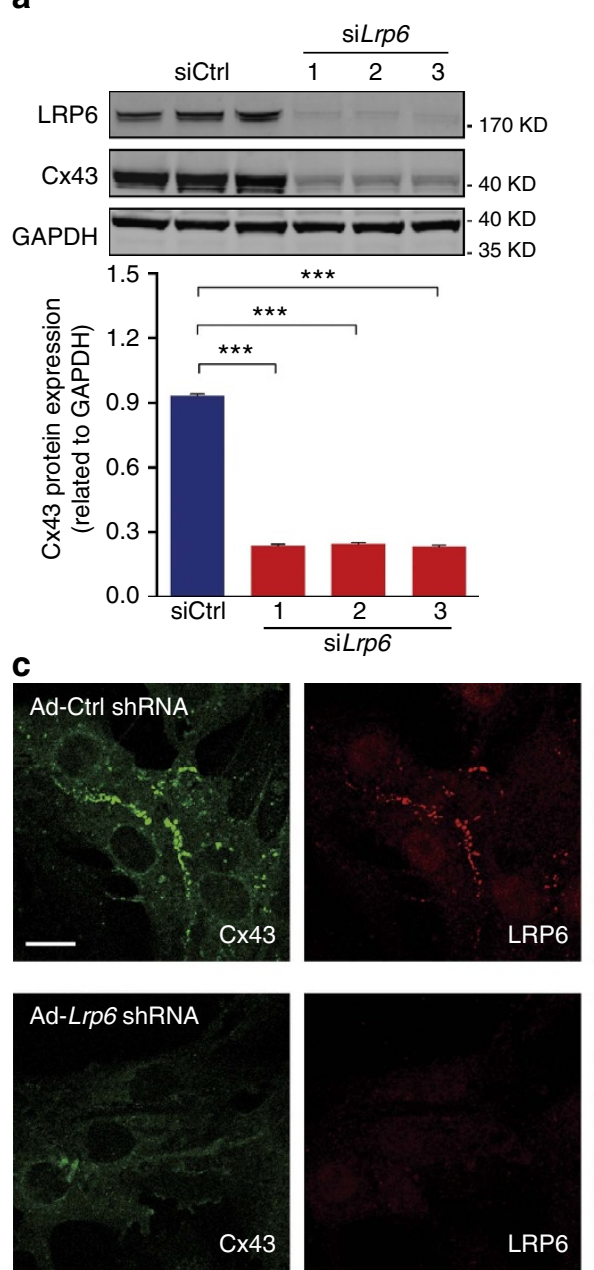

d
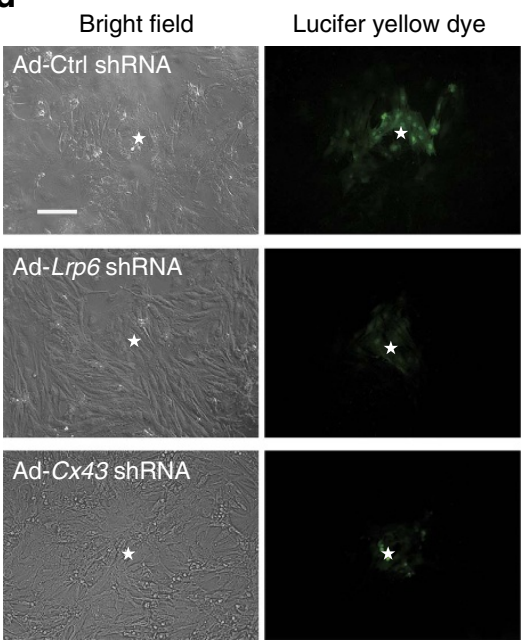

b
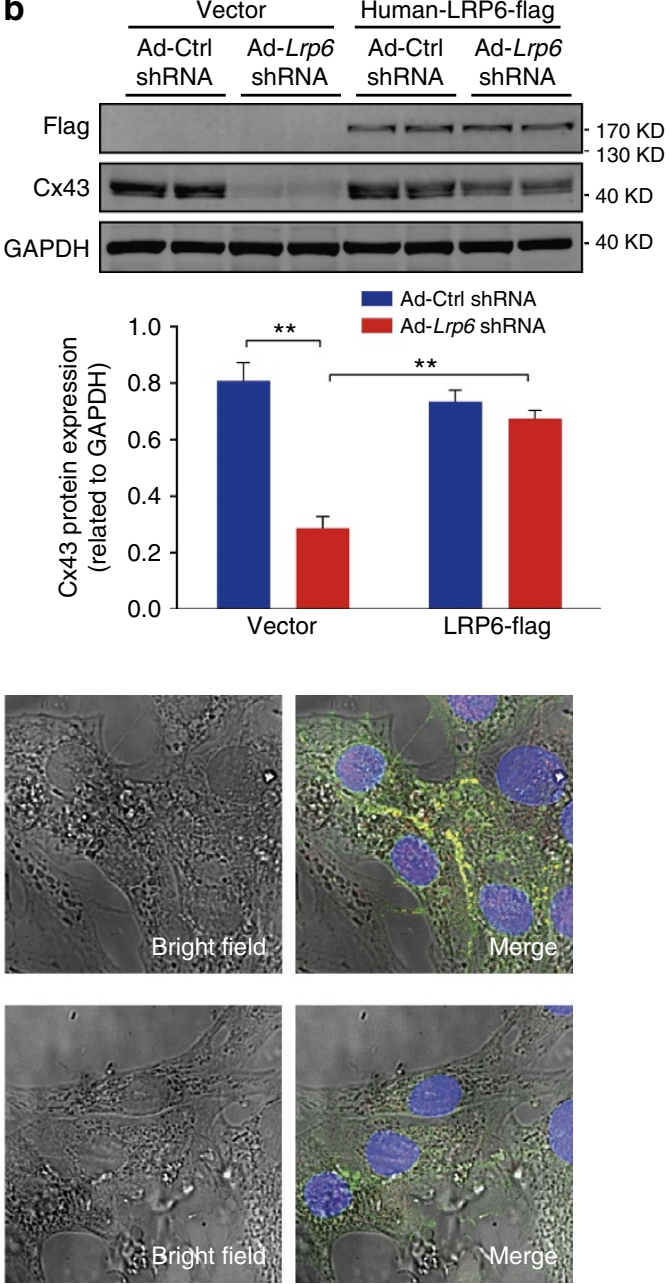

e

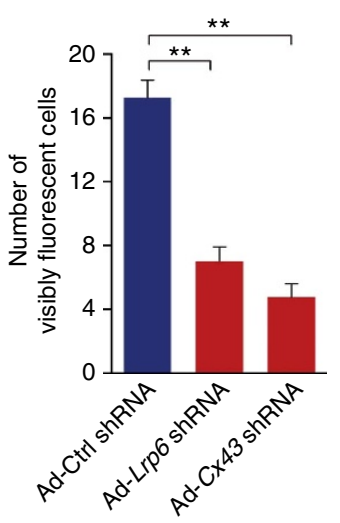

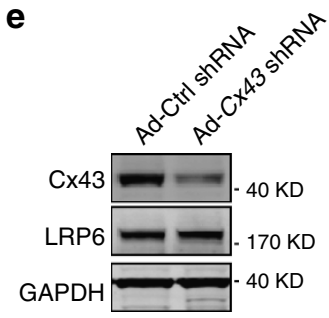

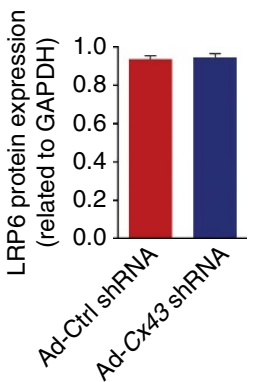

Figure 2 | A deficiency of LRP6 depresses the expression and function of Cx43. (a,b) Effects of Lrp6 knockdown on Cx43 protein levels in cultured NRVMs. Top, typical western blots; bottom, pooled data. Three independent $\operatorname{Lrp} 6$ siRNA sequences were employed. $n=3$ (a,b). Data are means \pm s.e.m. ${ }^{* \star *} P<0.001$ compared with ctrl by one-way analysis of variance (ANOVA) with Bonferroni's post hoc test. $n$ represents the number of experiments. (c) Immunofluorescence imaging of endogenous Cx43 gap junction in LRP6-deficient myocytes. Scale bar, $10 \mu$ m. The presented images are representative of three separate experiments. (d) Dye coupling in Lrp6 knockdown, Cx43 knockdown and control NRVMs. Photographs are taken at 1 min after Lucifer yellow dye injection and injected cardiomyocytes are indicated by asterisks. Scale bar, $10 \mu \mathrm{m}$. Note that $\operatorname{Lrp} 6$ or Cx43 knockdown significantly reduces dye coupling among cardiomyocytes. Left, typical images; right, pooled data. $n=3$. Data are means \pm s.e.m. ${ }^{\star \star} P<0.01$ compared with ctrl by one-way ANOVA with Bonferroni's post hoc test. $n$ represents the number of experiments. (e) Effects of $C x 43$ knockdown on LRP6 protein expression in NRVMs. Top, typical blots; bottom, pooled data. $n=3$. Data are means \pm s.e.m. $n$ represents the number of experiments. 


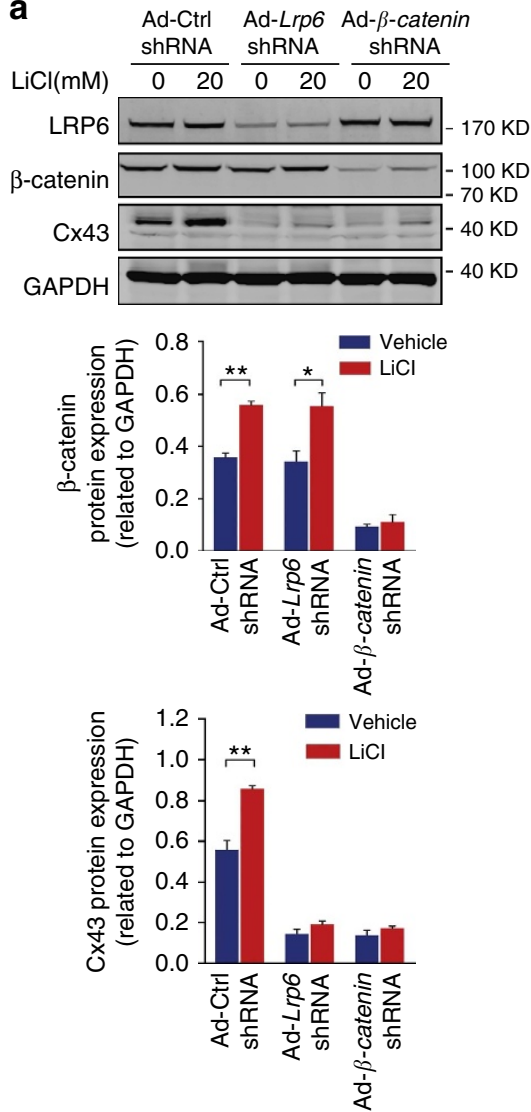

b
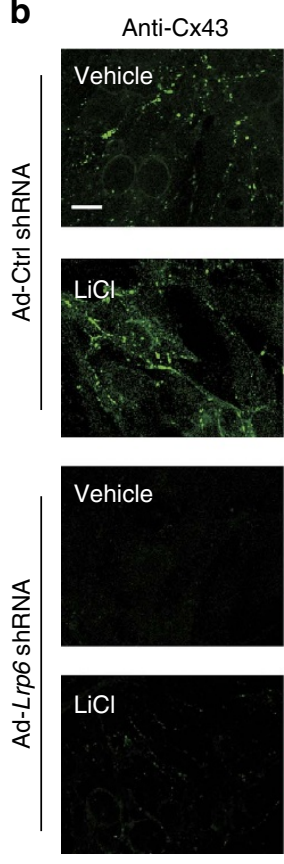
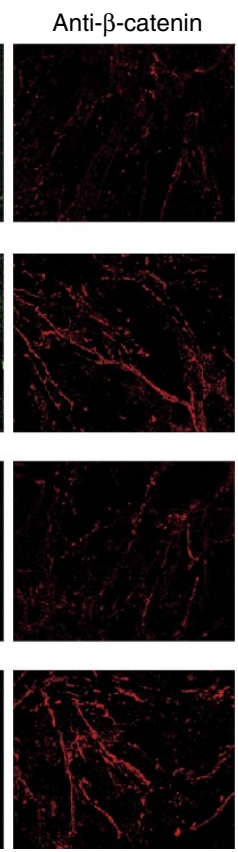
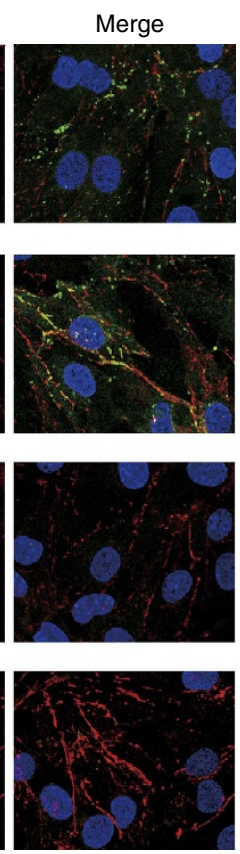

$\mathbf{C}$

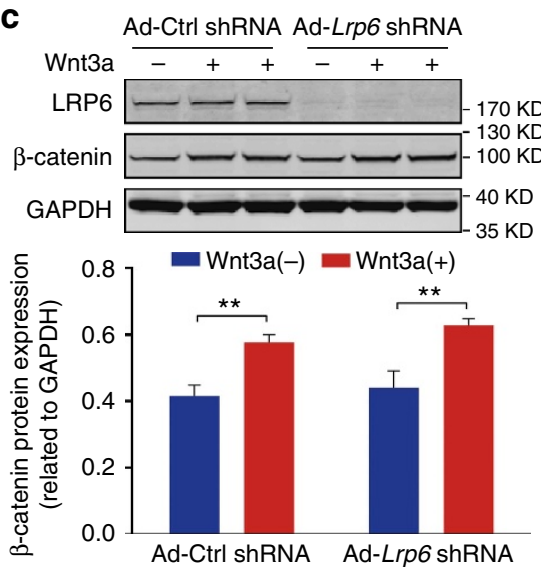

Figure 3 | LRP6 regulates Cx43 expression independent of Wnt/ $\boldsymbol{\beta}$-catenin signalling. (a) Effects of LiCl-mediated Wnt activation on Cx43 protein in LRP6-deficient NRVMs. Upper, typical blots; middle and lower, pooled data. (b) Immunomicroscopic view of Cx43 in LRP6-deficient NRVMs exposed to LiCI $(20 \mathrm{mM})$ for $24 \mathrm{~h}$. Scale bar, $10 \mu \mathrm{m}$. The presented images are representative of three separate experiments. (c) Evaluation of Wnt signalling activation in LRP6-deficient NRVMs treated with Wnt3a. The Wnt3a-conditioned medium was adopted to treat NRVMs expressing Ad-Lrp6 shRNA and the protein expression of $\beta$-catenin was examined. (d) Effects of Wnt signalling activation on Cx43 protein expression in LRP6-deficient NRVMs. Top, typical blots; bottom, pooled data. $n=3$ in $(\mathbf{a}, \mathbf{c}, \mathbf{d})$. Data are means \pm s.e.m. ${ }^{\star} P<0.05$ and ${ }^{\star \star} P<0.01$ compared with ctrl by two-tailed unpaired Student's $t$-test.

$n$ represents the number of experiments.

Wnt/ $\beta$-catenin signalling in the heart, and the regulation of $\mathrm{Cx} 43$ expression by LRP6 is independent of the $\mathrm{Wnt} / \beta$-catenin signalling pathway.

LRP6 modulates Cx43 expression post-transcriptionally. To gain insight into the reduction of $\mathrm{Cx} 43$ protein levels caused by LRP6 loss-of-function, changes in Cx43 transcription were investigated. Quantitative PCR analysis showed that LRP6 reduction did not change overall Cx43 messenger RNA (mRNA) levels, in contrast to the decreased $C \times 43$ mRNA levels caused by $\beta$-catenin knockdown (Fig. 4a,b). By transfecting a Cx43 promoter-reporter gene construct into human embryonic kidney 293 cells, we further measured the transcriptional activity of $C \times 43$ in the absence of LRP6. As shown in Fig. 4c, Lrp6 knockdown did not have any effect on Cx43 transcriptional activity. Collectively, the suppressive effect of LRP6 deficiency on the Cx43 protein was post-transcriptionally mediated. 


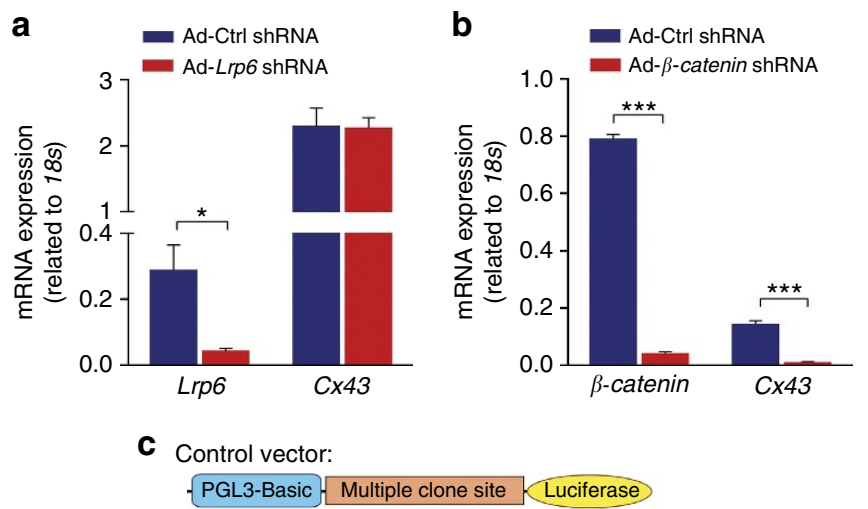

Gja1 promoter vector:
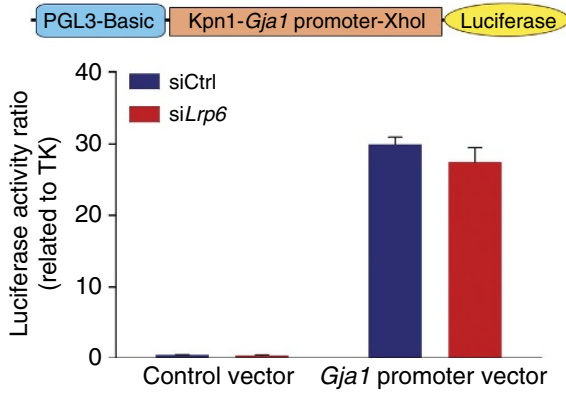

Figure 4 | LRP6 modulates Cx43 expression post-transcriptionally. (a) Quantitative PCR analysis of Cx43 transcript levels in Lrp6-knockdown NRVMs. ${ }^{\star} P<0.05$ compared with ctrl by two-tailed unpaired Student's t-test. (b) Effects of $\beta$-catenin knockdown on $C x 43$ mRNA expression. ${ }^{\star \star \star} P<0.001$ compared with $\mathrm{ctrl}$ by two-tailed unpaired Student's $t$-test. (c) Luciferase assay for the transcription of $C_{x} 43$. Top, schematic diagram of the luciferase report vector containing the $C_{x} 43$ (Gja1) promoter. LRP6deficient HEK 293 cells were transfected with a Gja1 promoter-reporter gene construct for $24 \mathrm{~h}$ before activity measurement. $n=3$. Data are means \pm s.e.m. $n$ represents the number of experiments.

LRP6 reduction induces degradation of the ER-trapped Cx43. The rapid turnover and specific plasma-membrane localization of $\mathrm{Cx} 43$ indicate that the intracellular movements of $\mathrm{Cx} 43$ proteins are highly regulated ${ }^{20}$. During the process of $\mathrm{Cx} 43$ protein turnover, nascent $\mathrm{Cx} 43$ proteins synthesized in the ER must be transported through the ER-Golgi network and intracellular transporting microtubules to their final destinations ${ }^{20-23}$. We monitored the dynamic trafficking of $\mathrm{Cx} 43$ using HeLa cells transfected with Cx43-green fluorescent protein (GFP). As shown in Supplementary Fig. 6a,b, the co-localization of LRP6 and Cx43 was most extensive in the ER at 5-h post transfection, and later on, their co-localization was mostly observed at the Golgi apparatus and along the microtubules (Supplementary Fig. 6b), suggesting that LRP6 constantly escorts Cx43 transport at the ER-Golgi interface and through the microtubule network to gap junction regions. Next, we assessed whether perturbed ER export contributed to $\mathrm{Cx} 43$ reduction in LRP6-deficient cardiomyocytes. As shown in Fig. 5a, in normal NRVMs transfected with Cx43-GFP, cell imaging displayed overt gap junction formation with very rare co-localization of $\mathrm{Cx} 43$ and PDI (an ER marker) at $24 \mathrm{~h}$ post transfection. In contrast, defective gap junctions and a significant overlap of $\mathrm{Cx} 43$ with PDI were observed in LRP6-deficient myocytes expressing Cx43-GFP. Notably, Cx43 strongly co-localized with GM130 in normal cardiomyocytes but not in LRP6-deficient cells (Fig. 5b). Despite the effect on Cx43 trafficking, Lrp6 knockdown did not significantly affect the ER and Golgi network (Fig. 5a,b).
Physiologically, $\mathrm{Cx} 43$ proteins exit the ER as monomers and subsequently oligomerize in the Golgi complex ${ }^{20,23}$. To further verify the LRP6 modulation on Cx43 trafficking through the ER-Golgi network, we analysed the oligomerization of $\mathrm{Cx} 43$ using gel filtration chromatography to distinguish connexin monomers from oligomers. The $\mathrm{Cx} 43$ expressed in normal NRVMs was resolved predominantly as two major fractions with sizes corresponding to monomeric and oligomerized $\mathrm{Cx} 43$. Lrp6 knockdown enriched the amount of $\mathrm{Cx} 43$ in the monomer band but, remarkably, reduced it in the oligomer band (Fig. $5 \mathrm{c}-\mathrm{e}$ ). These results indicate that LRP6 deficiency prevented the efficient trafficking of monomeric $\mathrm{Cx} 43$ from the ER to the Golgi apparatus and reduced the membrane expression of Cx43 proteins.

Cx43 proteins are short-lived and degrade through proteasomal/lysosomal pathways, whether $\mathrm{Cx} 43$ proteins are present in the secretory pathway (nascent connexins) or in gap junction plaques (mature connexins) ${ }^{24,25}$. The immature Cx43 monomers detained in the ER eventually enter the degradative pathway $^{26}$. We then examined whether aberrant $\mathrm{Cx} 43$ protein degradation contributed to $\mathrm{Cx} 43$ protein reduction in LRP6deficient cardiomyocytes. In NRVMs expressing Cx43-GFP, knockdown of Lrp6 facilitated the entry of $\mathrm{Cx} 43$ into the lysosomes (Fig. 5f). Treatment of LRP6-deficient NRVMs with leupeptin (a lysosomal protease inhibitor) greatly counteracted the reduction in $\mathrm{Cx} 43$ protein levels (Fig. 5g), which was similar to the effects of lysosomal-associated membrane protein-1 (Lamp1) siRNA and Bafilomycin Al (Ba-Al, an inhibitor of the late phase of autophagy; Supplementary Fig. $7 \mathrm{a}, \mathrm{b}$ ), whereas MG132 (a protease inhibitor) had no effect (Supplementary Fig. $7 \mathrm{c}, \mathrm{d})$. Moreover, we examined whether the reduced $\mathrm{Cx} 43$ by LRP6 deficiency was linked to the morphological and functional change in the ER. As shown in the Supplementary Fig. 8, neither the ER network nor the molecules for ER stress and protein exit machinery were affected. Taken together, LRP6 deficiency induces diversion of immature $\mathrm{Cx} 43$ proteins at the ER into lysosomal degradation, leading to $\mathrm{Cx} 43$ reduction.

Lack of LRP6 in cardiomyocytes predisposes to arrhythmia. To investigate whether LRP6 deficiency was also sufficient to downregulate $\mathrm{Cx} 43$ in myocardium tissue in vivo, we crossed mice bearing the $\operatorname{Lrp} f^{f l o x} / f l o x$ allele with a transgenic line ( $\mathrm{MerCreMer}$ ), which expresses Cre recombinase under the control of the $\alpha$-myosin heavy chain promoter in a tamoxifen-inducible cardiomyocyte-specific manner, to produce the conditional cardiac-specific Lrp6-knockout ( $\operatorname{Lrp6} 6 \mathrm{CKO})$ mice $\left(\operatorname{Lrp} 6^{f l o x / f l o x}\right.$; $\mathrm{Cre}^{+}{ }^{-}$mice). To inactivate the LRP6 gene specifically in the heart, $\operatorname{Lrp} 6^{\text {flox/flox }}$ mice with the Cre transgene were intraperitoneally administered tamoxifen (at E9.5 with a bolus injection and at 8 weeks old for 5 consecutive days, respectively). The Lrp6-CKO embryos demonstrated ventricular septal defect (Supplementary Fig. 9a), but the adult Lrp6-CKO animals appeared healthy and the Lrp6-CKO hearts were morphologically and functionally normal, as determined by histological analysis (Supplementary Fig. 9b,c) and echocardiographic measurements (Supplementary Fig. 9d). Histological analysis demonstrated that fibroblasts were interspersed throughout the myocardium and were accompanied by a small amount of collagen deposition (Supplementary Fig. 9c) in the Lrp6-CKO mice. Western blotting analyses of heart lysates revealed significant decreases in LRP6 and $\mathrm{Cx} 43$ proteins in Lrp6-CKO hearts compared with Cre transgene mice hearts (Fig. 6a). Quantitative PCR confirmed the reduction in Lrp6 mRNA transcripts, which had no effect on the mRNA expression of $\beta$-catenin and Cx43 (Fig. 6b). Lrp6-CKO did not change the nuclear localization of $\beta$-catenin (Fig. 6c). 
a
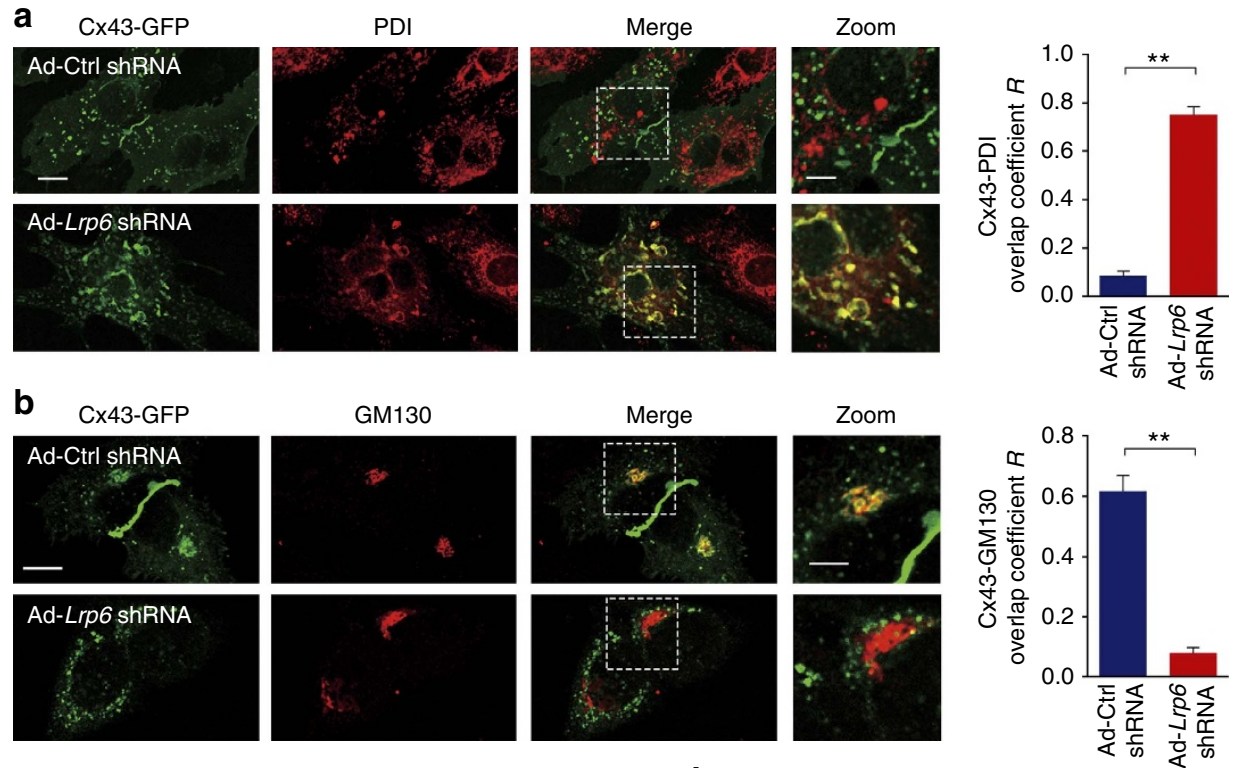

C
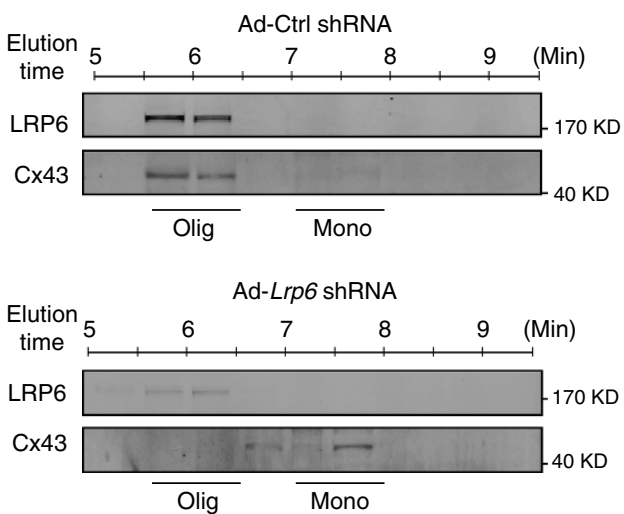

f

Cx43-GFP LysoTracker
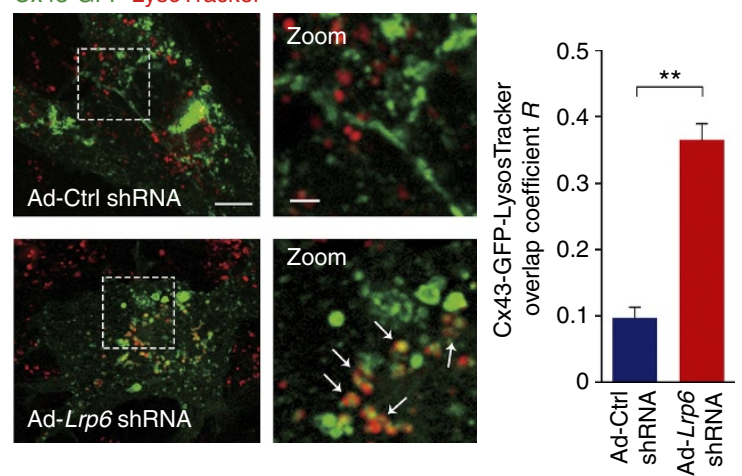

d

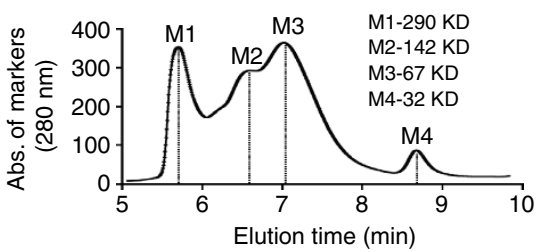

e

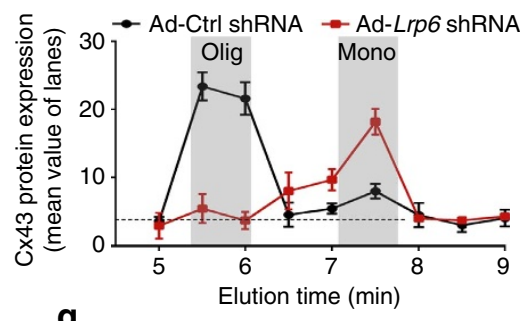

g

Ad-Lrp6

ShRNA --++--++

Leupeptin ---++++

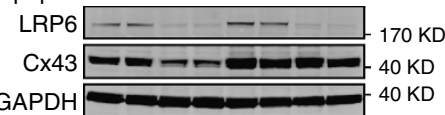

GAPDH

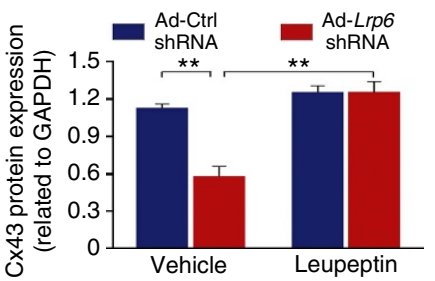

Figure 5 | The ER-arrested Cx43 is degraded in lysosomes by Lrp6 knockdown. (a,b) Immunofluorescence imaging of the co-localization of Cx43 with the ER and Golgi apparatus. PDI, an ER marker protein; GM130, a Golgi marker protein. Left, representative images; Scale bar, $10 \mu \mathrm{m}$. Right, analysis of overlap coefficient $R$. Scale bar for magnified images is $5 \mu \mathrm{m}$. The presented images are representative of three separate experiments. $n=3(\mathbf{a}, \mathbf{b})$. Data are mean \pm s.e.m. ${ }^{\star \star} P<0.01$ compared with ctrl by two-tailed unpaired Student's $t$-test. $n$ represents the number of experiments. (c) The fractionated samples by gel filtration chromatography were analysed using western blot analysis with SDS-PAGE. (d,e) Gel filtration chromatography separation of cardiomyocyte proteins. (d) Separation of standard proteins (M1-M4). M1, glutamine dehydrogenase, 290 KD; M2, lactate dehydrogenase, 142 KD; M3, enolase, 67KD; M4, adenylate kinase, 32KD. (e) Protein expression analysis of c. Olig, oligomers; Mono, monomers. $n=3$. Data are means \pm s.e.m. $n$ represents the number of experiments. (f) Imaging for co-localization analysis of Cx43 and lysosomes in NRVMs expressing Cx43-GFP. White arrows indicated the co-localization of $\mathrm{C} \times 43$ and lysosomes. Right, quantative analysis of $\mathrm{Cx} 43$-lysosome overlap. The presented images are representative of three separate experiments. Scale bar, $10 \mu \mathrm{m}$; Scale bar for magnified images is $3 \mu \mathrm{m}$. $n=3$. Data are means \pm s.e.m. ${ }^{\star \star} P<0.01$ compared with ctrl by two-tailed unpaired Student's $t$-test. $n$ represents the number of experiments. (g) Western blotting analysis of the effects of lysosomal inhibition on Cx43 protein expression in LRP6-deficient NRVMs. leupeptin (Leu) was adopted to inhibit lysosomal degradation. $n=3$. Data are means \pm s.e.m. ${ }^{\star \star} P<0.01$ compared with ctrl by one-way analysis of variance (ANOVA) with Bonferroni's post hoc test. $n$ represents the number of experiments. 
a

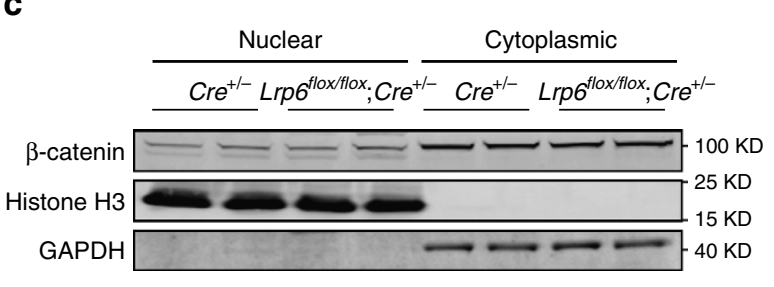

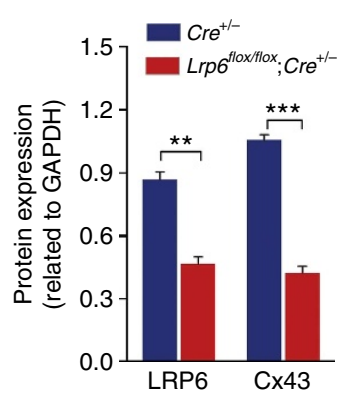

b

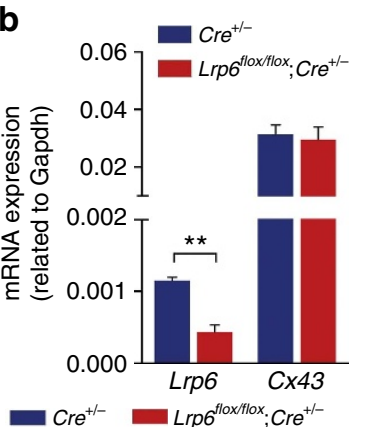

d
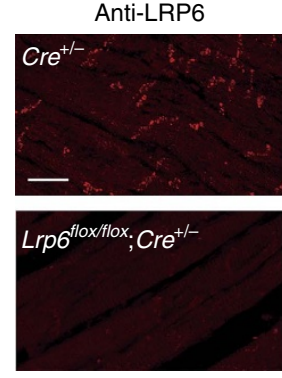

e

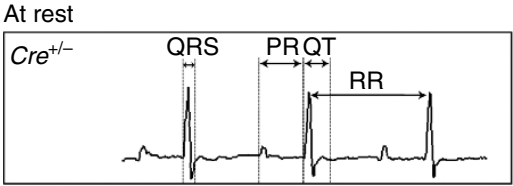

$\operatorname{Lrp6}^{\text {flox fllox}} ; \mathrm{Cre}^{+/-}$

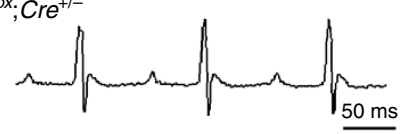

g
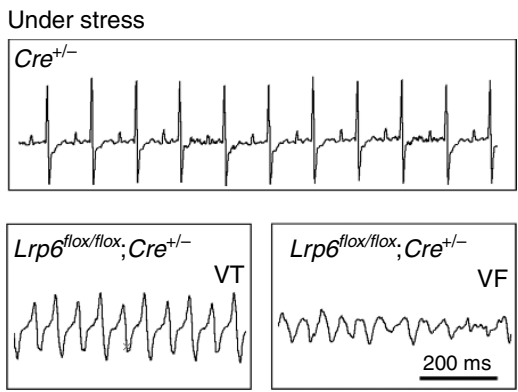
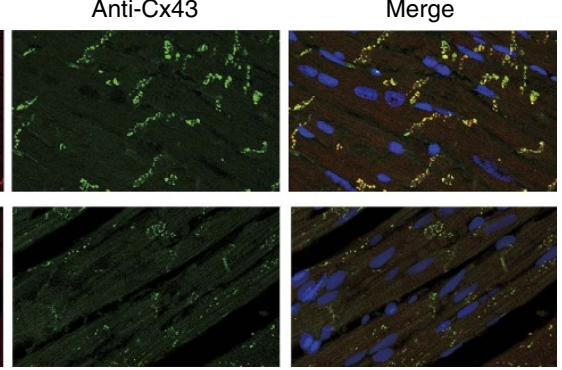

f

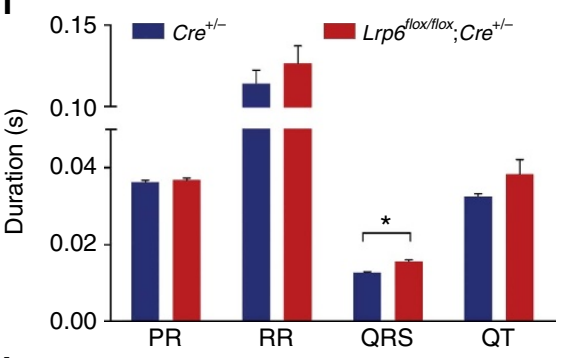

h

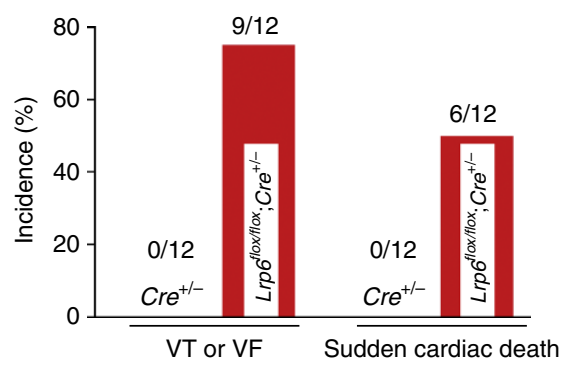

Figure 6 | Conditional cardiac-specific Lrp6-knockout impairs cardiac gap junctions. (a,b) Immunoblotting and quantitative PCR measurement of Lrp6 and Cx43 in Lrp6-knockout mice hearts. The presented blots (a) and PCR results (b) were obtained from five Lrp6-knockout mice and three Cre transgene animals. Data are means \pm s.e.m. ${ }^{\star \star} P<0.01$ and ${ }^{\star \star \star} P<0.001$ compared with $\mathrm{Cre}{ }^{+/-}$by two-tailed unpaired Student's $t$-test. (c) Cell fractional analysis of $\beta$-catenin protein in Lrp6-knockout mice hearts. Histone H3, a nuclear protein marker. Left, typical blots; right, pooled data. $n=3$. Data are means \pm s.e.m. $n$ represents the number of experiments. (d) Immunofluorescence staining of Cx43 and LRP6 in ventricular myocardium sections of cardiac-specific Lrp6-knockout mice and Cre transgene controls. Left, typical images; right, quantification of Cx43 expression at intercalated discs in five Lrp6-knockout mice and three Cre transgene animals. Scale bar, $25 \mu \mathrm{m}$. Data are means \pm s.e.m. ${ }^{\star \star} P<0.01$ compared with $C r e{ }^{+/-}$by two-tailed unpaired Student's $t$-test. $(\mathbf{e}, \mathbf{f})$ Analysis of resting ECGs parameters through a telemetric ECG recording system in conscious mice. Left, representative ECGs; right, pooled data. The presented ECGs (e) and statistical analysis (f) were obtained from twelve Lrp6-knockout mice and twelve Cre transgene animals. Data are means \pm s.e.m. ${ }^{\star} P<0.05$ compared with $\mathrm{Cre}^{+/-}$by two-tailed unpaired Student's $t$-test. (g) Representative ECG recordings of conscious cardiac-specific Lrp6-knockout mice and Cre transgene controls under stress conditions. VT, ventricular tachycardia; VF, ventricular fibrillation. (h) Statistical analysis of sudden cardiac deaths and VT/VF incidence. 
Immunofluorescence analyses of heart sections demonstrated significant reduction in $\mathrm{Cx} 43$ protein staining in the Lrp6-CKO hearts (Fig. 6d). A telemetric electrocardiograph recording of conscious Lrp6-CKO mice and Cre transgene mice revealed no significant difference in PR interval, heart rate and QT interval, but the duration of ventricular depolarization (QRS complex) was mildly prolonged in Lrp6-CKO mice (Fig. 6e,f). Moreover, the Lrp6-CKO mice between 6 and 8 weeks after tamoxifen administration were highly susceptible to ventricular tachycardia or fibrillation $(75 \%)$ and sudden cardiac death $(50 \%)$ when they were subjected to a stress-inducing protocol; conversely, no severe arrhythmia events were observed as mentioned above in Cre transgene control mice (Fig. 6g,h). These results suggest that cardiac Lrp6-knockout in vivo leads to marked downregulation of Cx43 gap junctions in intact hearts independently of Wnt signalling and consequently predisposes the hearts to lethal arrhythmias.

\section{Discussion}

The findings reported here elucidate the unanticipated Wnt/ $\beta$-catenin-independent scaffold function of LRP6 in regulating gap junctional coupling between individual cardiomyocytes. First, we identified the specific distribution of cardiac LRP6 within intercalated discs and the physical link between LRP6 and gap junction protein Cx43. Second, we revealed that LRP6 deficiency disrupts gap junction formation and function by impairing dynamics of Cx43 protein trafficking and stability. Third, we demonstrated that LRP6 reduction does not affect $\beta$-catenin protein expression in the presence or absence of a Wnt ligand. Fourth, the LRP6-dependent modulation of $\mathrm{Cx} 43$ is independent of $\beta$-catenin. Additionally, Lrp6-ablated mouse hearts showed defective $\mathrm{Cx} 43$ gap junctions but normal Wnt signalling and cardiac architecture. Taken together, these findings provide the first in vitro and in vivo evidence implicating LRP6 as an important platform for intracellular protein trafficking.

The biological significance of LRP6 has gained increasing recognition over the past decade. To date, our understanding of this protein is mostly limited to its critical roles in transducing canonical Wnt signalling 4,5 . LRP6-mediated Wnt signalling widely contributes to cell and tissue homeostasis ${ }^{5,12}$, and orients stem-cell division that determines distinct cell fate and organogenesis ${ }^{5,27}$. Alterations in the genes encoding LRP6 proteins disrupt the $\mathrm{Wnt} / \beta$-catenin signalling pathway and consequent cell behaviours. ${ }^{5}$. Unexpectedly, LRP6 is not necessary for Wnt signalling transduction in the heart, but it critically governs the formation and function of $\mathrm{Cx} 43$ gap junctions independent of Wnt/ $\beta$-catenin signalling (Figs 2 and 3 ). Intriguingly, although LRP5 and LRP6 are highly homologous proteins with key functions in canonical Wnt signalling, LRP5 does not contribute to the regulation of $\mathrm{Cx} 43$ gap junction (Supplementary Figs 1 and 3), further supporting the distinct biological property of LRP6 in Cx43-mediated intercellular communication.

Cx43 molecules constitute the integral gap junction channel. The short half-life and rapid turnover kinetics of $\mathrm{Cx} 43$ implicate an important mechanism for degradative regulation of intercellular coupling within the hear $\mathrm{t}^{24,25}$. In the present study, we observed a significant reduction in $\mathrm{Cx} 43$ protein levels when LRP6 was absent (Figs 2, 3 and 6). Similar to previous reports, which demonstrate that premature $\mathrm{Cx} 43$ in the ER is diverted from the secretory pathway to the degradation pathway ${ }^{28,29}$, we have characterized the defective transport of $\mathrm{Cx} 43$ from the ER to the Golgi apparatus and the pre-Golgi lysosomal degradation of newly synthesized Cx43 (Fig. 5), and our findings are in line with the concept that protein degradation by the ER occurs in the cytosol and lysosomes ${ }^{26}$. The LRP6-dependent modulation of Cx43 appears not to be involved in Cx43 transcription, or movement along microtubules, or internalization from the membrane surface (Fig. 4 and Supplementary Figs 6, 10 and 11), which differs from $\beta$-catenin-mediated regulation of $\mathrm{Cx} 43$ (Fig. 4 and Supplementary Fig. 11). Thus, our findings lead to the theory that, in the process of gap junction formation, LRP6 may act as a novel scaffold protein for intracellular $\mathrm{Cx} 43$ trafficking.

Intercellular communication is part of a complex system of communication that governs basic cellular activities and coordinates cell actions ${ }^{30}$. Gap junction residing at cell-cell borders is one of the most common ways in which human cells communicate ${ }^{30}$. Its density is of general importance. Cx43 is a most widely expressed and abundant gap junction protein throughout different tissues and critically governs intercellular signalling communication ${ }^{31,32}$. The loss of Cx43 gap junctional communication leads to developmental defects and tumourigenesis ${ }^{32,33}$. In the heart, gap junctions join the ends of cardiomyocytes and ensure electric coupling between cells $^{34}$. Following cardiac ischaemia, reduction of Cx43 gap junctions contributes to malignant arrhythmias ${ }^{35}$. Preventing or reversing this process offers a strategy to repair a damaged heart and ameliorate arrhythmogenesis ${ }^{36}$. Thus, the mechanistic characterization of LRP6-dependent regulation of $\mathrm{Cx} 43$ gap junction may have profound implications in development and diseases.

In conclusion, our findings identify a novel molecular property of LRP6 beyond its role as a Wnt co-receptor. The molecular identification of LRP6 as a regulator of gap junction formation in cardiomyocytes may provide novel insights into cardiac pathophysiology.

\section{Methods}

This study conformed to the Guide for the Care and Use of Laboratory Animals published by the US National Institutes of Health (NIH Publication, 8th Edition, 2011) and the policy of the Animal Care and Use Committee of the Tongji University School of Medicine.

Isolation of adult rat ventricular myocytes. Ventricular myocytes were isolated from the Langendorff-perfused hearts of adult Sprague Dawley rats ( 2 months old). Briefly, the heart was removed, mounted on the Langendorff apparatus and perfused with $\mathrm{Ca}^{2}+$-free Krebs-Henseleit bicarbonate buffer to wash out the blood. Then the heart was perfused with Krebs-Henseleit bicarbonate buffer containing $25 \mathrm{mg} \mathrm{ml}^{-1}$ of collagenase type II (Worthington) for $10 \mathrm{~min}$ for digestion. When the heart became flaccid, the atria and great vessels were removed, and the ventricle was cut into small pieces and filtered through a cell strainer $(100 \mu \mathrm{m}, \mathrm{BD}$ Falcon). The flow-through cells were then pelleted by centrifugation at $530 \mathrm{~g}$ for $3 \mathrm{~min}$ at room temperature and resuspended in $\mathrm{Ca}^{2+}$-free Tyrode's solution. The calcium concentration was then gradually increased to $1.2 \mathrm{mM}$ over $60 \mathrm{~min}$.

Immunofluorescence. Cells were fixed with $4 \%$ ice-cold paraformaldehyde (PFA) (Sigma) for $15 \mathrm{~min}$ and permeabilized with $0.1 \%$ Triton X-100 (Sigma) in PBS (Gibco) for $10 \mathrm{~min}$, followed by $30 \mathrm{~min}$ of blocking in 1\% BSA (Roche). The cells were then stained overnight at $4{ }^{\circ} \mathrm{C}$ with the following primary antibodies: sarcomeric $\alpha$-actinin (1:400; Sigma), LRP6 (1:100; Abcam), LRP5 (1:100; Abcam), Cx43 (1:200; Sigma), PDI (1:100; Novus), GM130 (1:100; CST), $\alpha$-tubulin (1:400 Sigma), Cx45 (1:200; Abcam), Cx40 (1:200; Abcam) and $\beta$-catenin (1:100; Sigma) Next, the cells were washed with PBS and incubated for $1 \mathrm{~h}$ with the respective secondary antibodies conjugated to Alexa Fluor 488/555/633 (1:300; Invitrogen), after which the cells were stained with ToTo-3 (Invitrogen) for an additional $20 \mathrm{~min}$ if needed.

Sections of mouse and rat hearts were deparaffinized and rehydrated, and then boiled in sodium citrate solution for $20 \mathrm{~min}$ for antigen retrieval. Slides were processed for immunofluorescence visualization according to the procedure used for cultured cardiomyocytes. Images were captured using a Leica SP5 laser confocal microscope with a $\times 63$ oil lens. Co-localization was analysed using Image-Pro Plus software (MediaCybernetics).

Western blot and immunoprecipitation analysis. For western blot analysis, cells and tissue homogenates were lysed in a protein-lysis buffer containing $50 \mathrm{mM}$ 
Tris- $\mathrm{HCl}, \mathrm{pH} 7.5,150 \mathrm{mM} \mathrm{NaCl}, 2 \mathrm{mM}$ EDTA, $1 \%$ NP40, $1 \%$ Triton and protease inhibitors (Roche). The lysate supernatant was collected after centrifugation, run on 10\% SDS-polyacrylamide gel electrophoresis (SDS-PAGE) gel (Invitrogen) and transferred to nitrocellulose membranes. The membranes were then incubated with the following primary antibodies: $\mathrm{Cx} 43$ (Sigma) at 1:8,000; LRP6 (CST) at 1:1,000; LRP5 (CST) at 1:1,000; $\beta$-catenin (Sigma) at 1:1,000; LAMP1 (Abcam) at 1:1,000; Flag (Sigma) at 1:1,000; $\mathrm{Cx} 45$ (Abcam) at 1:1,000; $\mathrm{Cx} 40$ (Abcam) at 1:1,000; $\mathrm{N}$-cadherin (CST) at 1:1,000; Histone H3 (Abcam) at 1:1,000; p-IRE1 $\alpha$ (CST) at 1:1,000; GRP78 (CST) at 1:1,000; CHOP (CST) at 1:1,000; Sarla (Abcam) at 1:1,000; Sarlb (Abcam) at 1:1,000; DNM2 (Abcam) at 1:1,000 and GAPDH (CST) at 1:1,000. The secondary antibodies conjugated to infrared dyes (LI-COR Biosciences) were applied at a concentration of 1:10,000 and visualized using an Odyssey imager. Western Blots were quantified by densitometry using ImageJ software (NIH). Full scans of western blots are presented in Supplementary Fig. 12.

For co-immunoprecipitation analysis, protein lysate was incubated overnight at $4{ }^{\circ} \mathrm{C}$ with the primary antibodies against Cx43 (Sigma), LRP6 (CST), LRP5 (CST), Flag (Sigma) or isotype control immunoglobulin G (Sigma) at a concentration of 1:50 with constant stirring. The next day, $50 \mu \mathrm{l}$ Dynabeads (Invitrogen) were added, and the mixture was incubated for $6 \mathrm{~h}$ at $4{ }^{\circ} \mathrm{C}$ with rotation. The bead-antibody complexes were collected. Next, the samples were analysed by regular western blot.

Quantitative PCR. To assess the mRNA expression levels of $L r p 6, C x 43, L r p 5$ and $\beta$-catenin in cells and heart tissues, RNA was extracted using TRI Reagent (Ambion) according to the manufacturer's protocol. complementary DNA was synthesized using the TaqMan Reverse Transcription Kit (Applied Biosystems). Quantitative PCR was then performed using the Power SYBR Green master mix (Applied Biosystems) on a 7,900 HT Real-Time PCR System (Applied Biosystems). The housekeeping gene Gapdh or $18 s$ was used for normalization. The sequences of all PCR primers are listed in Supplementary Table 1.

Isolation and transfection of neonatal rat ventricular myocytes. Ventricles from neonatal rats were separated from the atria, cut into small pieces $(\sim 2 \times 2$ $\mathrm{mm}^{2}$ ) and then dissociated in $\mathrm{Ca}^{2+}$-free HBSS containing $0.125 \mathrm{mg} \mathrm{ml}^{-1}$ trypsin (Gibco), $10 \mu \mathrm{g} \mathrm{ml}^{-1}$ DNase II (Sigma) and $0.1 \mathrm{mg} \mathrm{ml}^{-1}$ collagenase type IV (Sigma). Digestion was performed at $37^{\circ} \mathrm{C}$ by stirring the digestion solution containing the heart sections throughout the repeated 5-min period of digestion for 8-10 times. The supernatant was collected with FBS (Gibco) after each digestion period. After digestion, the collected supernatant was centrifuged at $600 \mathrm{~g}$ for $10 \mathrm{~min}$ at room temperature, and then cell pellets were resuspended in DMEM (Gibco) supplemented with $10 \%$ FBS and with $100 \mu \mathrm{M}$ 5-bromo-2'-deoxyuridine (Sigma). The resuspended cells were passed through a cell strainer $(100 \mathrm{~mm}, \mathrm{BD}$ Falcon) and seeded onto $100-\mathrm{mm}$ plastic dishes for $2 \mathrm{~h}$ at $37^{\circ} \mathrm{C}$ in a $5 \% \mathrm{CO}_{2}$ and humidified atmosphere. The supernatant was then collected and plated onto $1 \%$ gelatin (Sigma)-coated dishes. Twenty-four hours after the seeding, the medium was changed to DMEM (Gibco) containing 2\% FBS (Gibco), $1 \%$ insulin-transferrin-selenium (ITS; Gibco), 1\% Penicillin-Streptomycin (Gibco) and $100 \mu \mathrm{M}$ 5bromo-2'-deoxyuridine (Sigma).

For some gene silencing studies, cardiomyocytes were infected with adenoviral vectors expressing shRNAs against $L r p 6, C x 43, \operatorname{Lrp} 5$ or $\beta$-catenin at the MOI (multiplicity of infection) of 100 (Hanbio Co. Ltd, Shanghai, China) after $72 \mathrm{~h}$ of seeding. Meanwhile, siRNA against LAMP1 and three independent siRNAs against Lrp5 or Lrp6 were transfected using Lipofectamine RNAiMAX (Invitrogen) after $72 \mathrm{~h}$ of cardiomyocytes seeding. All shRNA and siRNA sequences are listed in Supplementary Tables 2 and 3. Twenty-four hours after the treatment of adenoviral shRNAs, Lrp6, Lrp5 and Cx43 were overexpressed by transfecting their respective plasmids using Lipofectamine 3,000 (Invitrogen).

Plasmids and reagents. Plasmids expressing LRP6, LRP5 or Cx43 were purchased from Origene. LiCl, leupeptin, MG132, nocodazole and dynasore were all purchased from Sigma. Brefeldin A and LGK-974 were purchased from Selleck. Bafilomycin A1 was purchased from Sangon Biotech in Shanghai.

Lucifer yellow dye transfer. Neonatal myocytes were cultured on $35-\mathrm{mm}$ glass-bottom dishes. Individual myocytes were injected with Lucifer Yellow ( $4 \% \mathrm{wt} / \mathrm{vol}$ in $150 \mathrm{mM} \mathrm{LiCl}$ ) via microelectrodes $(20 \mathrm{M} \Omega$ when filled with $\mathrm{KCl})$ using overcompensation of the negative capacitance circuit on an electrometer (World Precision Instruments, Sarasota, Florida, USA) until the cell glowed brightly ( $<1 \mathrm{~min}$ ). Cells were viewed under a Leica microscope equipped with fluorescence illumination and FITC filters, and pictures were captured every $30 \mathrm{~s}$ over a period $2 \mathrm{~min}$.

Wnt3a treatment. The cell line stably expressing Wnt3a was a kind gift from Dr Xiaoqing Zhang (Tongji University School of Medicine, China). Cells were grown in a T75 flask at a density of $2 \times 10^{5}$ per flask in DMEM containing $10 \%$ FBS (Gibco). When cells grew to $70 \%$ confluence, the medium was replaced by DMEM without serum and further cultured for another 2 days. The medium was then collected and centrifuged at $600 \mathrm{~g}$ for $10 \mathrm{~min}$, and the supernatant was stored at $4^{\circ} \mathrm{C}$. After myocytes were transfected using Ad-shRNAs for $24 \mathrm{~h}$, the myocyte medium was replaced with the above pre-warmed wnt3a-conditioned medium every day. Myocytes were harvested after another $48 \mathrm{~h}$ of culture and analysed by western blot.

Reporter gene assay. To construct a luciferase reporter plasmid for the $C x 43$ promoter, a fragment containing the human Gjal promoter region was amplified from human genomic DNA by PCR using specific primers (F: $5^{\prime}$-GGGGTAC CCAACTGACAAATTGCTTAT-3'; R: 5'-CCGCTCGAGGCTCTCAG ACCTGTCTGT- $3^{\prime}$ ) and inserted into the luciferase plasmid (pGL3). To examine the effect of LRP6 deficiency on the activity of the Gja1 promoter, HEK 293 cells were transfected with siLrp6 or siCtrl, and, $24 \mathrm{~h}$ later, the Gja1 promoter luciferase reporter plasmid was transfected using Lipofectamine 3,000 (Invitrogen).

After another $24 \mathrm{~h}$ of incubation, luciferase activities were measured using a dual luciferase reporter assay system (Promega).

Isolation of membrane fractions from myoctyes. Myocytes were washed twice with ice-cold PBS and harvested in physiological buffer (10 mM Tris-HCl (pH 7.4), $5 \mathrm{mM}$ EDTA, $2 \mathrm{mM}$ dithiothreitol (DTT), $1 \mathrm{mM}$ phenylmethyl sulphonyl fluoride (PMSF), $2 \mu \mathrm{g} \mathrm{ml}^{-1}$ leupeptin, $2 \mu \mathrm{g} \mathrm{ml}^{-1}$ pepstatin A, $140 \mathrm{mM} \mathrm{NaCl} ; 800 \mu \mathrm{l}$ per 100 -mm dish). The cells were homogenized via 30 strokes with a Dounce homogenizer and were then centrifuged at $500 \mathrm{~g}$ at $4^{\circ} \mathrm{C}$ for $10 \mathrm{~min}$. The collected supernatant was further centrifuged at $100,000 \mathrm{~g}$ for $60 \mathrm{~min}$ at $4^{\circ} \mathrm{C}$. The supernatant was the cytosolic fraction. The pellet was resuspended in PBS containing 1\% Triton $\mathrm{X}-100$, and the solubilized proteins were designated as the membrane fractions. Each fraction was analysed by SDS-PAGE.

Isolation of nuclear fractions from myocytes. Myocytes were collected and centrifuged for $5 \mathrm{~min}$ at $450 \mathrm{~g}$. The cell pellet was resuspended in lysis buffer ( $10 \mathrm{mM}$ Tris- $\mathrm{HCl}, \mathrm{pH} 7.5$, with $2 \mathrm{mM} \mathrm{MgCl}, 3 \mathrm{mM} \mathrm{CaCl}_{2}$ and $0.3 \mathrm{M}$ Sucrose, $1 \mathrm{mM}$ DTT, $1 \mathrm{mM}$ PMSF, $2 \mu \mathrm{g} \mathrm{ml}^{-1}$ leupeptin and $2 \mu \mathrm{g} \mathrm{ml}^{-1}$ pepstatin A). The cells were homogenized with five up-and-down strokes in a glass tissue homogenizer, and then centrifuged for $20 \mathrm{~min}$ at $10,000 \mathrm{~g}$. The supernatant is the cytoplasmic fraction. The crude nuclei pellet was resuspended in extraction buffer (20 mM HEPES, pH 7.9, with $1.5 \mathrm{mM} \mathrm{MgCl}, 0.42 \mathrm{M} \mathrm{NaCl}, 0.2 \mathrm{mM}$ EDTA, $25 \%$ (v/v) Glycerol and $1 \mathrm{mM}$ DTT, $1 \mathrm{mM}$ PMSF, $2 \mu \mathrm{g} \mathrm{ml}^{-1}$ leupeptin and $2 \mu \mathrm{gl}^{-1}$ pepstatin A), gently shaked for $30 \mathrm{~min}$ and centrifuged for $5 \mathrm{~min}$ at $20,000 \mathrm{~g}$. The supernatant is the final nuclear fraction. Each fraction was analysed by SDS-PAGE.

Gel filtration chromatography. Gel filtration chromatography was used for determination of $\mathrm{Cx} 43$ monomers and oligomers. Myocytes were washed twice with ice-cold PBS and harvested in physiological buffer $(10 \mathrm{mM}$ Tris- $\mathrm{HCl}(\mathrm{pH} 7.4), 5 \mathrm{mM}$ EDTA, $2 \mathrm{mM}$ DTT, $1 \mathrm{mM}$ PMSF, $2 \mu \mathrm{g} \mathrm{ml}^{-1}$ leupeptin, $2 \mu \mathrm{g} \mathrm{ml}^{-1}$ pepstatin A, $140 \mathrm{mM} \mathrm{NaCl} ; 800 \mu \mathrm{l}$ per $100-\mathrm{mm}$ dish). The cells were homogenized via 30 strokes with a Dounce homogenizer and were then centrifuged at $500 \mathrm{~g}$ at $4^{\circ} \mathrm{C}$ for $10 \mathrm{~min}$. $1 \%$ Triton X-100 was added to solubilize the membrane protein. After $1 \mathrm{~h}$ of incubation, the sample was centrifuged in a Beckman TLA 100.3 rotor at 55,000 r.p.m. $(100,000 \mathrm{~g})$ for $30 \mathrm{~min}$ at $4^{\circ} \mathrm{C}$. Before gel filtration chromatography, the TSK-GEL G2000SW $\mathrm{XL}_{\mathrm{X}}$ (TSK Company Ltd, Japan) column was equilibrated with $20 \mathrm{mM}$ of phosphate buffer, pH 7.0. Then the supernatant obtained after centrifugation was filtered through a syringe filter with a pore size of $0.2 \mu \mathrm{m}$ and applied to the column. Sample volumes were maintained at $<0.5 \mathrm{ml}$. A flow rate of $1 \mathrm{ml} \mathrm{min}{ }^{-1}$ was used. Fractions were collected every $30 \mathrm{~s}$ throughout a period of $12 \mathrm{~min}$. Next, these fractions were analysed by $10 \%$ SDS-PAGE and immunoblotting.

Generation of conditional cardiac-specific Lrp6-knockout mice. Previously generated $\alpha M H C / M e r C r e M e r$ mice were mated with $L r p 6^{\text {flox/flox }}$ mice (kindly gifted by Dr Bart O. Williams, Center for Skeletal Disease and Tumor Metastasis and Laboratory of Cell Signaling and Carcinogenesis, Van Andel Research Institute, Grand Rapids, Michigan, USA) to produce $\alpha M H C / M e r C r e M e r ; ~ L r p 6^{\text {flox/flox }}$ animals. The mice were maintained with a mixed C57BL genetic background. They were treated with tamoxifen (Sigma) via intraperitoneal injection once a day for 5 consecutive days at a dosage of $80 \mathrm{mg}$ per $\mathrm{kg}$ of body weight per day. To study the potential effects of LRP6 on embryonic heart development, the mice on pregnancy days 9.5 were intraperitoneally treated with tamoxifen via a bolus injection.

ECG recording. Telemetric ambulatory long-term ECG recordings were obtained with implantable transmitters. Mice were anaesthetized with ketamine hydrochloride $\left(100 \mathrm{~m} \mathrm{~kg}^{-1}\right.$, intraperitoneal injection (IP)) and pentobarbital $\left(30 \mathrm{mg} \mathrm{kg}^{-1}, \mathrm{IP}\right)$, and a midline incision was made along the spine. An implantable 3.5-g wireless radiofrequency transmitter (DataSciences International) was aseptically inserted into a subcutaneous tissue pocket in the peritoneum. The mice were placed in cages overlying a receiver for transmission of ECG signals to a computer for display and analysis, including assessment of heart rate variability parameters. The inducible arrhythmic events were tested according to the stress protocol with epinephrine $\left(2 \mathrm{mg} \mathrm{kg}^{-1}\right.$, IP) plus caffeine $\left(120 \mathrm{mg} \mathrm{kg}^{-1}, \mathrm{IP}\right)$ in both the knockout and age-matched Cre transgene littermates. 
Echocardiography analysis. To evaluate left ventricular function and dimension, transthoracic two-dimensional echocardiography was performed on mice sedated with 5\% isoflurane using a Visual Sonics Vevo 770 ultrasound system (Visual Sonics) equipped with a $30-\mathrm{MHz}$ linear array transducer. M-mode tracings in the parasternal short axis view were used to measure left ventricular anterior and posterior wall thicknesses and left ventricular internal diameters at end-systole and end-diastole, which were used to calculate left ventricular fractional shortening and the ejection fraction according to standard formulas.

Heart collection and histological analysis. At the end of the above experiments, animals were anaesthetized with $5 \%$ isoflurane and then killed by injection with $10 \% \mathrm{KCl}$ to stop the heart at diastole. The hearts were excised, briefly washed in PBS, weighed, fixed in $10 \%$ formalin at room temperature, embedded in paraffin and further processed for histology. Haematoxylin-eosin and Masson's trichrome staining were performed according to standard procedures, and samples were analysed for regular morphology and the extent of fibrosis.

Quantification of Cx43 gap junction plaque. ImageJ software was used to subtract the background from each image, and the rolling ball radius was set at 10.00 pixels. For each sample, the fluorescence intensity of six randomly selected images containing $\sim 20$ intercalated discs was analysed.

Statistics. All data are presented as the means \pm s.e.m. Statistical analyses were performed using Prism Software (GraphPad). The statistical significance of the difference between two sets of data was assessed using an unpaired, two-tailed Student's $t$-test and one-way analysis of variance with Bonferroni's post hoc test. A $P$ value $<0.05$ was considered to be significant.

Data availability. All relevant data are available from the authors on request and are included with the manuscript.

\section{References}

1. Nusse, R. \& Varmus, H. E. Wnt genes. Cell 69, 1073-1087 (1992).

2. Cadigan, K. M. \& Nusse, R. Wnt signaling: a common theme in animal development. Genes Dev. 11, 3286-3305 (1997).

3. Logan, C. Y. \& Nusse, R. The Wnt signaling pathway in development and disease. Annu. Rev. Cell Dev. Biol. 20, 781-810 (2004).

4. Tamai, K. et al. LDL-receptor-related proteins in Wnt signal transduction. Nature 407, 530-535 (2000).

5. Joiner, D. M., Ke, J., Zhong, Z., Xu, H. E. \& Williams, B. O. LRP5 and LRP6 in development and disease. Trends Endocrinol. Metab. 24, 31-39 (2013).

6. Rao, T. P. \& Kühl, M. An updated overview on Wnt signaling pathways: a prelude for more. Circ. Res. 106, 1798-1806 (2010).

7. Gessert, S. \& Kühl, M. The multiple phases and faces of wnt signaling during cardiac differentiation and development. Circ. Res. 107, 186-199 (2010).

8. Zhou, Y. et al. Canonical WNT signaling components in vascular development and barrier formation. J. Clin. Invest. 124, 3825-3846 (2014).

9. Bergmann, M.W. WNT signaling in adult cardiac hypertrophy and remodeling: lessons learned from cardiac development. Circ. Res. 107, 1198-1208 (2010).

10. Malekar, P. et al. Wnt signaling is critical for maladaptive cardiac hypertrophy and accelerates myocardial remodeling. Hypertension 55, 939-945 (2010).

11. Naito, A. T., Shiojima, I. \& Komuro, I. Wnt signaling and aging-related heart disorders. Circ. Res. 107, 1295-1303 (2010).

12. Pinson, K. I., Brennan, J., Monkley, S., Avery, B. J. \& Skarnes, W. C. An LDLreceptor-related protein mediates Wnt signalling in mice. Nature 407, 535-538 (2000).

13. Mani, A. et al. LRP6 mutation in a family with early coronary disease and metabolic risk factors. Science 315, 1278-1282 (2007).

14. Xu, Y. et al. Functional analysis LRP6 novel mutations in patients with coronary artery disease. PLoS ONE 9, e84345 (2014).

15. Severs, N. J. The cardiac gap junction and intercalated disc. Int. J. Cardiol. 26, 137-173 (1990)

16. Van Kempen, M. J., Fromaget, C., Gros, D., Moorman, A. F. \& Lamers, W. H. Spatial distribution of connexin43, the major cardiac gap junction protein, in the developing and adult rat heart. Circ. Res. 68, 1638-1651 (1991).

17. Olson, D. J., Christian, J. L. \& Moon, R. T. Effect of wnt-1 and related proteins on gap junctional communication in Xenopus embryos. Science 252, 1173-1176 (1991).

18. van der Heyden, M. A. et al. Identification of connexin 43 as a functional target for Wnt signalling. J. Cell Sci. 111, 1741-1749 (1998).

19. Ai, Z., Fischer, A., Spray, D. C., Brown, A. M. \& Fishman, G. I. Wnt-1 regulation of connexin 43 in cardiac myocytes. J. Clin. Invest. 105, 161-171 (2000).

20. Martin, P. E., Blundell, G., Ahmad, S., Errington, R. J. \& Evans, W. H. Multiple pathways in the trafficking and assembly of connexin 26, 32 and 43 into gap junction intercellular communication channels. J. Cell Sci. 114, 3845-3855 (2001).

21. Majoul, I. V. et al. Limiting transport steps and novel interactions of Connexin43 along the secretory pathway. Histochem. Cell Biol. 132, 263-280 (2009).

22. Giepmans, B. N. et al. Gap junction protein connexin- 43 interacts directly with microtubules. Curr. Biol. 11, 1364-1368 (2001).

23. Lauf, U. et al. Dynamic trafficking and delivery of connexons to the plasma membrane and accretion to gap junctions in living cells. Proc. Natl Acad. Sci. USA 99, 10446-10451 (2002).

24. Saffitz, J. E., Laing, J. G. \& Yamada, K. A. Connexin expression and turnover implications for cardiac excitability. Circ. Res. 86, 723-728 (2000).

25. Smyth, J. W. \& Shaw, R. M. The gap junction life cycle. Heart Rhythm $\mathbf{9}$, 151-153 (2012).

26. Lippincott-Schwartz, J., Bonifacino, J. S., Yuan, L. C. \& Klausner, R. D. Degradation from the endoplasmic reticulum: disposing of newly synthesized proteins. Cell 54, 209-220 (1988).

27. Habib, S. J. et al. A localized Wnt signal orients asymmetric stem cell division in vitro. Science 339, 1445-1448 (2013).

28. Das, S. et al. ERp29 restricts Connexin43 oligomerization in the endoplasmic reticulum. Mol. Biol. Cell 20, 2593-2604 (2009).

29. Maza, J., Das Sarma, J. \& Koval, M. Defining a minimal motif required to prevent connexin oligomerization in the endoplasmic reticulum. J. Biol. Chem 280, 21115-21121 (2005).

30. Ruch, R. J. Intercellular communication, homeostasis, and toxicology. Toxicol. Sci. 68, 265-266 (2002).

31. Naus, C. C. \& Laird, D. W. Implications and challenges of connexin connections to cancer. Nat. Rev. Cancer 10, 435-441 (2010).

32. Kameritsch, P., Khandoga, N., Pohl, U. \& Pogoda, K. Gap junctional communication promotes apoptosis in a connexin-type-dependent manner. Cell Death Dis. 4, e584 (2013).

33. Chatterjee, B. et al. Developmental regulation and expression of the zebrafish connexin43 gene. Dev. Dyn. 233, 890-906 (2005).

34. Gros, D. B. \& Jongsma, H. J. Connexins in mammalian heart function. Bioessays 18, 719-730 (1996).

35. Lerner, D. L., Yamada, K. A., Schuessler, R. B. \& Saffitz, J. E. Accelerated onset and increased incidence of ventricular arrhythmias induced by ischemia in Cx43-deficient mice. Circulation 101, 547-552 (2000).

36. Danik, S. B. et al. Modulation of cardiac gap junction expression and arrhythmic susceptibility. Circ. Res. 95, 1035-1041 (2004).

\section{Acknowledgements}

This work was supported by the National Key Basic Research Program of Chin (2013CB531100, to Y.-H.C.), the Major International Joint Research Program of China (81120108004, to Y.-H.C.), the Key Program of National Natural Science Foundation of China (81530017, to Y.-H.C.), the National Innovative Research Groups Program of the National Natural Science Foundation of China (81221001, to Y.-H.C.) and the General Program of National Natural Science Foundation of China (81170224 and 81270313, to J.L.; 31271214, to Y.-H.C.)

\section{Author contributions}

Y.H.C. and J.L. conceived and designed this study. J.L., C.L., D.L., F.L., T.Y., E.T., X.M., Y.W., L.Z., D.X., S.W., Y.L., J.H., J.S., Y.L., D.S., L.X. and L.L. performed the experiments J.L., C.L., L.P. and Y.H.C. analysed the data. J.L., L.P., J.C. W.Z. and Y.H.C. provided discussions and advice. Y.H.C. and J.L. wrote the manuscript. Y.H.C. supervised the project.

\section{Additional information}

Supplementary Information accompanies this paper at http://www.nature.com/ naturecommunication

Competing financial interests: The authors declare no competing financial interests

Reprints and permission information is available online at http://npg.nature.com/ reprintsandpermissions/

How to cite this article: Li, J. et al. LRP6 acts as a scaffold protein in cardiac gap junction assembly. Nat. Commun. 7:11775 doi: 10.1038/ncomms11775 (2016).

This work is licensed under a Creative Commons Attribution 4.0 International License. The images or other third party material in this article are included in the article's Creative Commons license, unless indicated otherwise in the credit line; if the material is not included under the Creative Commons license, users will need to obtain permission from the license holder to reproduce the material To view a copy of this license, visit http://creativecommons.org/licenses/by/4.0/ 